\title{
Identificación molecular de Flavobacterium psychrophilum y caracterización de las alteraciones cutáneas en la trucha arcoíris (Oncorhynchus mikyss) procedente de Puno, Perú
}

\section{Molecular identification of Flavobacterium psychrophilum and characterization of cutaneous alterations in rainbow trout (Oncorhynchus mikyss) from Puno, Peru}

\section{Carlos Távara P. ${ }^{1}$, Enrique Serrano-Martínez ${ }^{1,3}$, Carolina Tafalla ${ }^{2}$, Cesar Burga C. ${ }^{1}$,} Luis Llanco A. ${ }^{1}$

\section{Resumen}

\begin{abstract}
El presente estudio tuvo por objetivo comparar las lesiones histológicas de truchas arcoíris (Oncorhynchus mikyss) afectadas por la Enfermedad Bacteriana del Agua Fría (BCDW) con muestras de piel de truchas asintomáticas procedentes de centros piscícolas en el Lago Titicaca (Puno, Perú) e identificar la presencia de Flavobacterium psychrophilum mediante PCR convencional. Se trabajó con 13 truchas con lesiones de piel y siete sin lesiones, con tallas superiores a los $25 \mathrm{~cm}$ y peso promedio de $350 \mathrm{~g}$. En el PCR para la identificación de F. psychrophilum se utilizaron iniciadores dirigidos a la región 16S ARNr. Molecularmente, ambos grupos de animales resultaron positivos para la presencia de F. psycrophilum. Se puede concluir que este patógeno está presente en la zona sur del país.
\end{abstract}

Palabras clave: Flavobacterium psychrophilum; PCR; histología; Oncorhynchus mikyss

\section{Abstract}

The aim of this study was to compare histological lesions of rainbow trout (Oncorhynchus mikyss) affected by the bacterial cold water disease (BCDW) with asymptomatic trout skin samples from fish farms in Lake Titicaca (Puno, Peru) and identify the presence of Flavobacterium psychrophilum by conventional PCR. Thirteen trout with skin lesions and seven without lesions, with sizes greater than $25 \mathrm{~cm}$ and average

${ }^{1}$ Grupo SANIVET, Facultad de Medicina Veterinaria y Zootecnia, Universidad Peruana Cayetano Heredia, Lima, Perú

${ }^{2}$ Centro de Investigación en Sanidad Animal (CISA-INIA), Madrid, España

${ }^{3}$ E-mail: enrique.serrano@upch.pe

Recibido: 27 de diciembre de 2018

Aceptado para publicación: 5 de octubre de 2019 
weight of $350 \mathrm{~g}$ were used. Conventional PCR was performed for the identification of Flavobacterium psychrophilum, using primers directed to the $16 \mathrm{~S}$ rRNA region. Molecularly, both groups of animals were positive for the presence of $F$. psycrophilum. It can be concluded that this pathogen is present in the southern part of the country.

Keywords: Flavobacterium psychrophilum; PCR; histology; Oncorhynchus mikyss

\section{INTRODUCCIÓN}

La Oficina de Estudios Económicos del Ministerio de la Producción del Perú reportó que la producción nacional de trucha creció en $800 \%$ en la última década (PRODUCE, 2017). Sin embargo, dada las prácticas sanitarias inadecuadas, la proliferación de patógenos es una constante entre los acuicultores. Según Mateo et al. (2016), para el caso de Perú, Yersinia ruckeri, Aeromonas salmonicida y Flavobacterium psychrophilum son los principales agentes infecciosos que amenazan la truchicultura nacional.

La piel es una de las primeras líneas de defensa de los peces contra los patógenos transmitidos por el agua. En estos animales la piel no está queratinizada de modo que las células de la epidermis están en contacto directo con el ambiente acuático y deben responder inmediatamente a la exposición a patógenos (Salinas, 2015).

El agente causal de la Enfermedad Bacteriana del Agua Fría (BCDW) es Flavobacterium psychrophilum, siendo la trucha arcoíris especialmente susceptible (Ramsrud et al., 2007). Según Crump et al. (2005), las mayores pérdidas ocurren en alevines, con mortalidades acumuladas de hasta $90 \%$ (Nilsen et al., 2011). Esta enfermedad también afecta a peces en etapas juveniles y adultos (Antaya et al., 2008), siendo característica la presencia de úlceras en la región dorsal y la melanosis de la piel. La flavobacteriosis se encuentra globalmente distribuida (Nicolas et al., 2008) y Perú no es la excepción (León et al., 2009). El aislamiento e identificación de esta bacteria es dificultoso debido a los exigentes requerimientos nutricionales y condiciones de cultivo (Nematollahi et al., 2003), de allí que se emplean técnicas moleculares de mayor sensibilidad, como PCR, para confirmar el diagnóstico (Toyama et al., 1994; Bader et al., 1998; Urdaci et al., 1998).

Los reportes de flavobacteriosis son escasos en el país; sin embargo, se sabe que el problema está latente. En el presente trabajo se identifica la presencia de Flavobacterium psychrophilum no solo en peces con sintomatología clínica, sino también en peces asintomáticos.

\section{Materiales y Métodos}

\section{Lugar de Estudio y Peces}

El estudio se campo se realizó en el Lago Titicaca, zonas de Chucuito, Pomata y Juli, departamento de Puno, Perú, donde existe una intensa actividad piscícola. Entre los parámetros físicoquímicos del agua se registraron temperaturas entre 14 y $18{ }^{\circ} \mathrm{C}, \mathrm{pH}$ entre 7 y 7.5 y salinidad entre 4 y 7 ups. Estos parámetros son adecuados para el cultivo de trucha a pesar de la ligera elevada salinidad del lago. Las muestras se trabajaron con la debida autorización de los productores. 
Se trabajo con truchas arcoíris Oncorhynchus mikyss de $350 \mathrm{~g}$ y de $25 \mathrm{~cm}$ aproximadamente, cultivadas en jaulas, con sintomatología de flavobacteriosis (nado errático, melanosis, úlceras dorsales y esplecnomegalia) y que no había recibido tratamiento antibiótico $(n=13)$. Así mismo con siete truchas clínicamente sanas de la misma poza (Figura 1).

\section{Muestras y Análisis}

Los peces se sacrificaron por sobredosis de benzocaína $(50 \mathrm{mg} / \mathrm{l})$ (Sigma-Aldrich, USA). Se tomaron muestras de piel de todos los peces que se conservaron en formol al $10 \%$ y luego en parafina para el análisis histológico. Secciones de los mismos tejidos se guardaron en solución RNAlater (Invitrogen, USA) para el diagnóstico por PCR. Así mismo, muestras de riñón anterior, bazo e hígado fueron sembrados en agar Cytophaga (Himedia, India) e incubados por $96 \mathrm{~h}$ a $20^{\circ} \mathrm{C}$.

\section{Extracción de ARN y Preparación de ADNc}

El ARN total se extrajo de muestras de piel utilizando el kit SV Total RNA Isolation System (Promega, USA), siguiendo las instrucciones del fabricante. Los pellets de ARN se resuspendieron en agua libre de RNasa. En seguida, se usó $1 \mu \mathrm{g}$ de RNA para obtener cDNA de cada muestra usando el GoScript ${ }^{\mathrm{TM}}$ Reverse Transcription System (PROMEGA), siguiendo las instrucciones del fabricante y se almacenó a $-20{ }^{\circ} \mathrm{C}$ hasta su uso.

\section{Identificación de $F$. psychrophilum por PCR}

Los cebadores empleados para el PCR convencional (forward GCAATCTACCTTTTACAGAGGGATAGCCC y reverse CTCCTACGGGAGGCAGCAGTGAGGA) se diseñaron para detectar el gen rRNA 16S de F. psychrophilum. Se utilizó un Thermo Scientific TM Termociclador Artik, con un volumen de reacción de $25 \mu$ para cada reacción, que incluyó $18.5 \mu \mathrm{l}$ de $\mathrm{H}_{2} \mathrm{O}$ libre de DNAsa, $2.5 \mu$ l de Buffer 10X, $1 \mu 1$ de $\mathrm{MgCl}_{2}$, $0.5 \mu 1$ de dNTPs, $0.5 \mu 1$ del cebador Forward y $0.5 \mu 1$ del Reverse ( 10 pmol de ambos), 0.75 $\mu l$ de Taq DNA Polymerase y $1 \mu \mathrm{de}$ cDNA.

El protocolo de PCR incluyó una desnaturalización inicial de $95^{\circ} \mathrm{C}$ por $5 \mathrm{~min}$, seguido por 35 ciclos de amplificación, que incluyeron una desnaturalización a $95^{\circ} \mathrm{C}$ por $30 \mathrm{~s}$, hibridación a $55^{\circ} \mathrm{C}$ por 30 s y elongación a $72{ }^{\circ} \mathrm{C}$ por $30 \mathrm{~s}$, con un paso de elongación final a $72{ }^{\circ} \mathrm{C}$ por $7 \mathrm{~min}$. Para la electroforesis, se tomó una alícuota de $10 \mu 1$ de cada muestra, combinada con GelRed ${ }^{\circledR}$ Nucleic Acid Gel Stain «Biotium» $(10 \mu \mathrm{l} / 100 \mathrm{ml})$ y corrida en gel de agarosa al $1.5 \%$, a $100 \mathrm{~V}$ por 45 min. Se usó el 100 bp DNA ladder (Promega, USA) $(4 \mu \mathrm{l})$ como marcador molecular. Los amplicones luego fueron visualizados bajo luz UV en un transiluminador (UVP BioDoc- $\mathrm{It}^{\mathrm{TM}}$ Imaging System), donde la presencia de un amplicón de 239 pb se consideró como positivo para F. psychrophilum.

Los amplicones fueron secuenciados para confirmar la identidad de la bacteria en estudio. Como control positivo se utilizó la cepa ATCC 49418 de F. psycrophilum, como control negativo se empleó los DNA de $Y$. ruckeri ATCC 29473, E. coli ATCC 25922 y A. salmonicida subsp salmonicida ATCC 33658, y como blanco agua libre de nucleasas (Sigma, USA). Los productos generados del PCR convencional, previamente secuenciados, fueron analizados con los programas Chromas Lite 2.0 y Blastn.

\section{Histología}

Las muestras de piel fueron teñidas con hematoxilina, según protocolo convencional de tinción (Bancroft y Gamble, 2008) y analizadas en microscopio óptico Leica DM 500. 

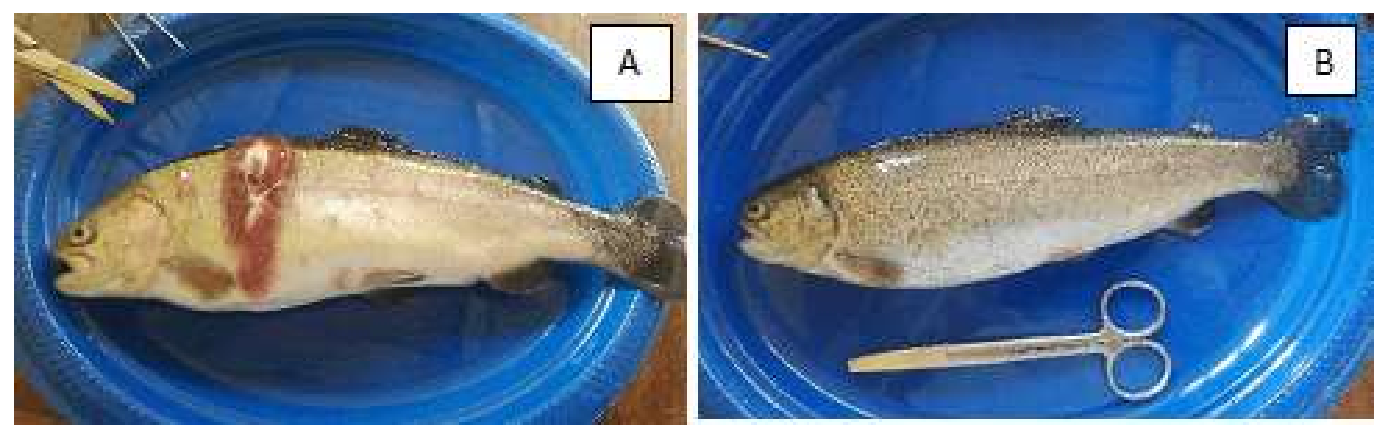

Figura 1. Trucha sintomática (A) y asintomática de Flavobacterium psychrophilum

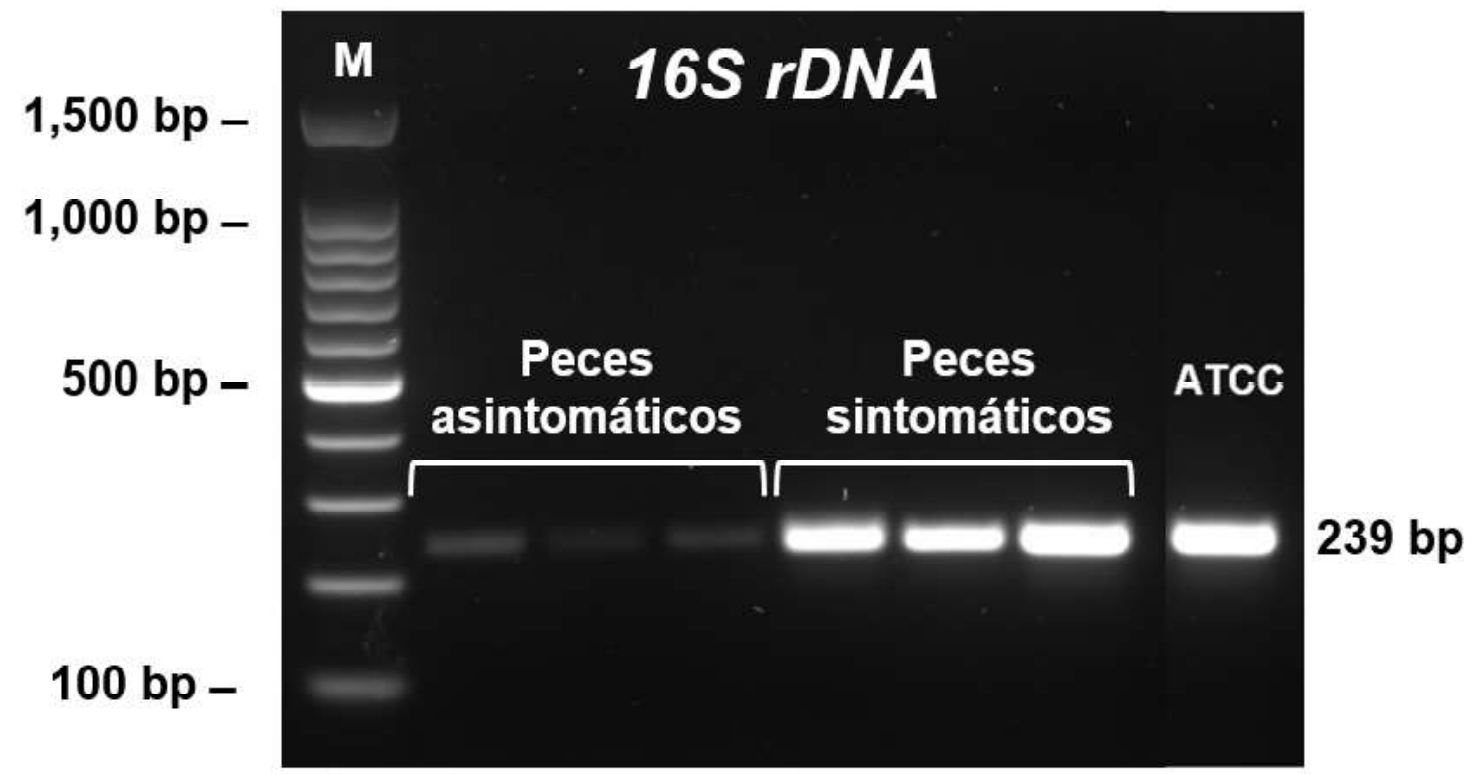

Figura 2. Detección de Flavobacterium psychrophilum por PCR convencional en truchas arcoíris Oncorhynchus mikyss. M (marcador): 100 bp (DNA ladder (Promega, USA)

\section{Resultados}

En el análisis microbiológico no se encontraron colonias compatibles con $F$. psycrophilum. En el análisis por PCR convencional de los cDNA de la piel truchas sintomáticas y asintomáticas (Figura 1) se detectó el amplicón del tamaño esperado (Figura 2), indicando que ambos grupos de peces estaban infectados con Flavobacterium psychrophilum. Ninguna muestra resultó negativa.

Los productos de PCR fueron secuenciados (Figura 3) pudiéndose confirmar $100 \%$ de similitud con Flavobacterium psychrophilum mediante el programa Blastn.

Se comparó la arquitectura microscópica de la piel intacta (Figura 4a) de peces asintomáticos respecto a una zona cercana a 


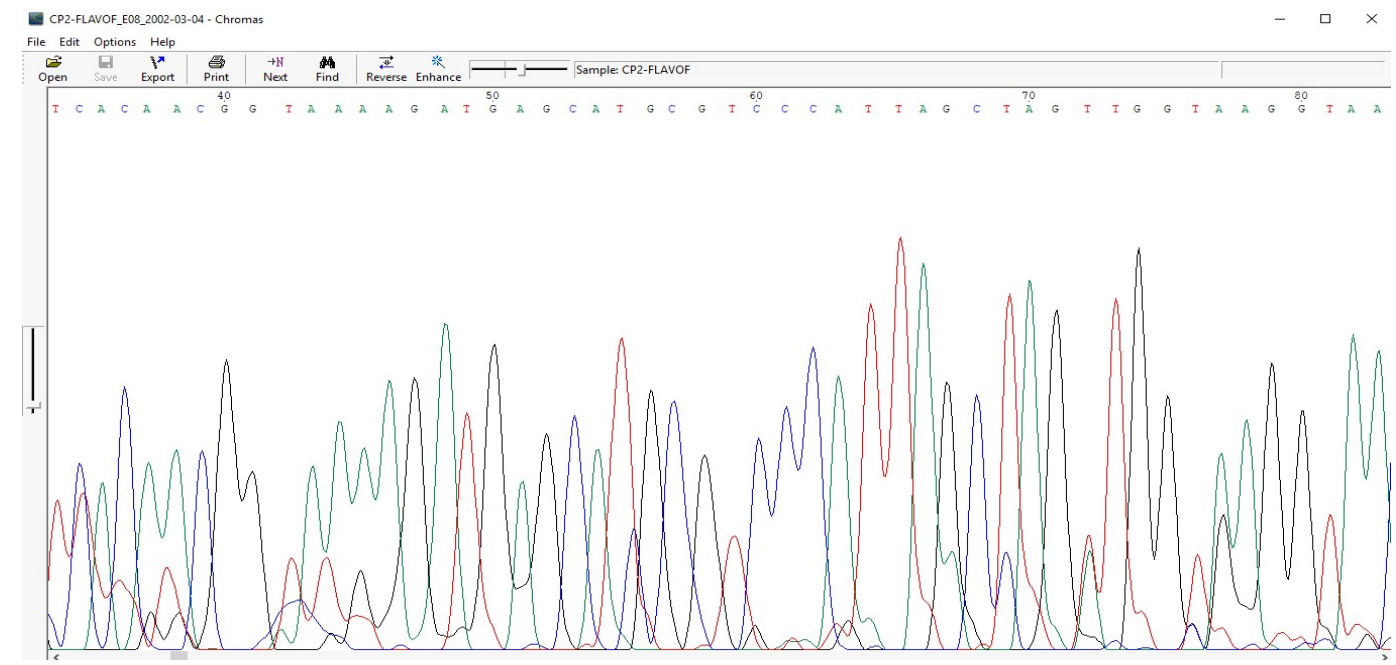

Figura 3. Cromatograma del producto de PCR para identificar Flavobacterium psycrophilum en muestras de piel de truchas arcoíris Oncorhynchus mikyss

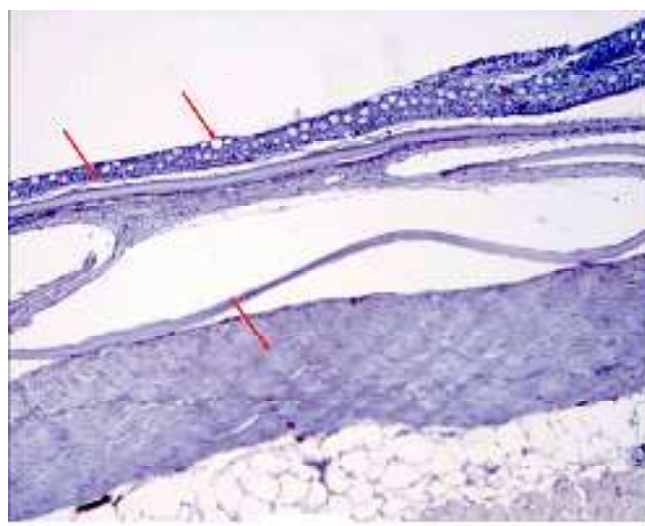

(a)

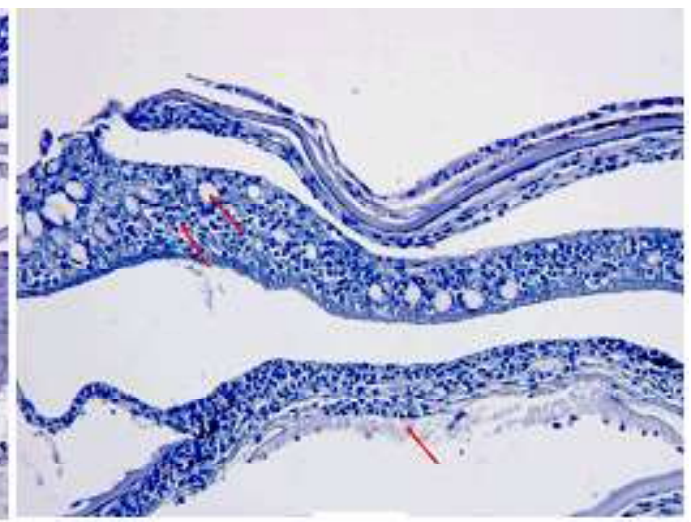

(b)

Figura 4. Corte histológico de piel de trucha arcoíris Oncorhynchus mikyss. (a) muestra de piel asintomática. (b) muestra de piel cercana a herida. Nótese la pérdida de arquitectura, disminución del número de células de goblet y aumento de linfocitos en la piel afectada (flechas)

una herida (Figura 4b) de truchas sintomáticas. En el primer caso se observó una disposición normal de linfocitos y células mucosas y la estructura uniforme de la dermis; mientras que en el caso del tejido cercano a la piel con herida se observó hiperplasia linfocítica, hipoplasia e hipertrofia de células goblet (caliciformes) y destrucción de la dermis.

\section{Discusión}

Se verificó mediante PCR la presencia de F. psychrophilum en muestras de piel, observando que, aunque esta bacteria también podía identificarse en peces aparentemente sanos, los amplicones fueron de me- 
nor intensidad que aquellos encontrados en animales con signología clara, sugiriendo una mayor carga bacteriana en los animales afectados. Casos de flavobacteriosis han sido reportados en Huancayo, Perú (León et al., 2009) en órganos internos de alevines de 5-7 $\mathrm{cm}$, identificados por métodos microbiológicos convencionales. En forma similar, Gonzales (2013) detectó $F$. psychrophilum en truchas de 25-35 cm cultivadas en el Lago Titicaca, realizando cultivos en medio Agar Tripticasa de Soya (TSA) desde varios órganos, incluido la piel. En el presente trabajo, se intentó aislar esta bacteria en agar Cytophaga con resultados negativos. El aislamiento e identificación de esta bacteria es dificultoso debido a sus requerimientos nutricionales y condiciones de cultivo exigentes (Nematollahi et al., 2003).

Por otro lado, Orieux et al. (2013) detectaron F. psychrophilum por PCR en peces asintomáticos durante el curso de un brote de enfermedad bacteriana del agua fría (BCWD). En cualquier caso, la detección de F. psychrophilum en la piel de individuos aparentemente sanos sugiere que estos peces actúan como reservorios que dispersan las bacterias en las aguas circundantes (Madetoja et al., 2000).

El ingreso de F. psychrophilum determina que se segregue una proteasa psicrófila (Bertolini et al., 1994) que crea perforaciones en la membrana celular para obtener $\mathrm{Ca}$, necesario para una mayor activación de esta enzima (Secades et al., 2001). Una vez que atraviesa la dermis, F. psychrophilum se propaga a través del colágeno de la matriz extracelular, por el cual tiene una gran afinidad, y se expande a través de la musculatura (Miwa y Nakayasu, 2005). A continuación, se producen úlceras abiertas, con lesiones posteriores en los órganos internos (Evensen y Lorenzen, 1996). De acuerdo con estos autores, histológicamente se observa hiperplasia de linfocitos e hipertrofia junto a hipoplasia de glándulas goblet en el tejido cir- cundante a la piel lesionada, produciendo menos moco en respuesta al ataque bacteriano. La destrucción de la dermis es debida probablemente a la proliferación de bacterias en el músculo de la trucha arcoíris, tal como lo afirman Miwa y Nakasayu (2005).

\section{Conclusiones}

- Se detectó Flavobacterium psychrophilum en truchas del Lago Titicaca, Perú, tanto en individuos aparentemente sanos como en aquellos con lesiones de piel.

- En las lesiones cutáneas se observa una fuerte respuesta tisular mediada por células linfocitarias.

\section{Agradecimientos}

Los autores agradecen a FONDECYTCONCYTEC por el apoyo financiero brindado al programa de Maestría en Sanidad Acuícola de la UPCH (Convenio de Gestión N. ${ }^{\circ}$ 230-2015 FONDECYT-De-PROMOCIÓN 2), que permitió los análisis y la capacitación técnica de los investigadores para la ejecución del estudio. Del mismo modo, se agradece a los piscicultores y tesistas que colaboraron durante la recolección de muestras. Carlos Távara también agradece a Vitapro S.A. por el compromiso con la investigación en la acuicultura del Perú, siendo parte del soporte financiero del presente trabajo.

\section{Literatura Citada}

1. Antaya C. 2008. Current ecoeconomical impacts of Flavobacterium psychrophilum. MMG 445 Basic Biotechnol J 4: 7-12.

2. Bader JA, Shotts EB. 1998. Identification of Flavobacterium and Flexibacter species by species-specific polymerase chain reaction primers to the $16 \mathrm{~S}$ ribosomal RNA gene. J Aquat Anim Health 10: 311-319. doi: 10.1577/15488667(1998)010<0311:IOFAFS $>2.0$. CO 2 
3. Bancroft JD, Gamble M. 2008. Theory and practice of histological techniques. $6^{\text {th }}$ ed. USA: Elsevier. 725 p.

4. Bertolini JM, Wakabayashi H, Watral VG, Whipple MJ, Rohovec JS. 1994. Electrophoretic detection of proteases from selected strains of Flexibacter psychrophilus and assessment of their variability. J Aquat Anim Health 6: 224233. doi: 10.1577/1548-8667(1994)006 $<0224$ :EDOPFS $>2.3 . \mathrm{CO} ; 2$

5. Crump E, Burian J, Allen P, Kay W. 2005. Identification and expression of a host-recognized antigen, FspA, from Flavobacterium psychrophilum. Microbio-logy 151:3127-3135. doi: 10.1099/ mic. $0.28140-0$

6. Evensen O, Lorenzen E. 1996. An immunohistochemical study of Flexibacter psychrophilus infection in experimentally and naturally infected rainbow trout (Oncorhynchus mykiss) fry. Dis Aquat Organ 25: 53-61. doi: 10.3354/dao025053

7. Gonzales J. 2013. Flavobacteriosis on rainbow trout (Oncorhynchus mykiss) from Lake Titicaca, Puno, Peru. 2009. Biologist 11: 205-215.

8. León J, Avalos R, Ponce M. 2009. Flavobacterium psychrophilum y su patología en alevines de Onchorhynchus mykiss del centro piscícola El Ingenio, Huancayo. Rev Per Biol 15: 117124. doi: 10.15381/rpb.v15i2.1737

9. Madetoja J, Nyman P, Wiklund T. 2000. Flavobacterium psychrophilum, invasion into and shedding by rainbow trout Oncorhynchus mykiss. Dis Aquat Organ 43: 27-38. doi: 10.3354/dao043027

10. Mateo EC, Castro T, Sierralta V, Mateo DR. 2016. Bacteriological and histopathological study of farmed rainbow trout, Oncorhynchus mykiss, in Peru. J Fish Dis 40: 941-946. doi: 10.1111/jfd.12555

11. Miwa S, Nakayasu C. 2005. Pathogenesis of experimentally induced bacterial- cold-water disease in ayu Plecoglossus altivelis. Dis Aquat Organ 67: 93-104. doi: 10.3354/dao067093

12. Nematollahi A, Decostere A, Pasmans F, Haesebrouck F. 2003. Flavobacterium psychrophilum infections in salmonid fish. J Fish Dis 26: 563-74. doi: 10.1046/j.1365-2761.2003.00488.x

13. Nicolas P, Mondot S, Achaz G, Bouchenot C, Bernardet JF, Duchaud E. 2008. Population structure of the fishpathogenic bacterium Flavobacterium psychrophilum. Appl Environ Microb 74: 3702-3709. doi: 10.1128/AEM.00244-08

14. Nilsen H, Olsen AB, Vaagnes Ø, Hellberg H, Bottolfsen K, Skjelstad H, Colquhoun DJ. 2011. Systemic Flavobacterium psychrophilum infection in rainbow trout Oncorhyn-chus mykiss (Walbaum) farmed in fresh and brackish water in Norway. J Fish Dis 34: 403-408. doi: 10.1111/j.1365-2761.2011.01249. $\mathrm{x}$

15. Orieux N, Douet DG, Le Hénaff $M$, Bourdineaud JP. 2013. Prevalence of Flavobacterium psychrophilum bacterial cells in farmed rainbow trout: characterization of metallothionein A and interleukin 1-â genes as markers overexpressed in spleen and kidney of diseased fish. Vet Microbiol 162: 127-135. doi: 10.1016/j.vetmic.2012.08.015

16. [PRODUCE] Ministerio de la Producción. 2017. Anuario estadístico pesquero y acuícola 2017. [Internet]. Disponible en: http://ogeiee.produce.gob.pe/ images/Anuario/Pesca_2017.pdf

17. Ramsrud AL, LaFrentz SA, LaFrentz BR, Cain KD, Call DR. 2007. Differentiating 16S rRNA alleles of Flavobacterium psychrophilum using a simple PCR assay. J Fish Dis 30: 175-180. doi: 10.1111/j.1365-2761.2007.-00795.x

18. Salinas I. 2015. The mucosal immune system of teleost fish. Biology 4: 525539. doi: 10.3390/biology4030525 
19. Secades P, Alvarez B, Guijarro JA. 2001. Purification and characterization of a psychrophilic, calcium-induced, growthphasedependent metalloprotease from the fish pathogen Flavo-bacterium psychrophilum. Appl Envi-ron Microb 67: 2436-2444. doi: 10.1128/AEM.67.6.2436-2444.2001

20. Toyama T, Kita-Tsukamoto K, Wakabayshi H. 1994. Identification of Cytophaga psychrophila by PCR targeted 16S ribosomal RNA. Fish Pathol 29: 271-275. doi: 10.3147/jsfp.29.271

21. Urdaci MC, Chakroun C, Faure D, Bernardet JF. 1998. Development of polymerase chain reaction assay for identification and detection of the fish pathogen Flavobacterium psychrophilum. Res Microbiol 149: 519-530. doi: 10.1016/S0923-2508(98)80006-5 